\title{
Cercopagis pengoi (Cladocera) in the Gulf of Finland: environmental variables affecting its distribution and interaction with Bosmina coregoni maritima
}

\author{
Arno Põllumäe $\mathrm{a}^{\mathrm{a}}$ and Katrin Väljataga ${ }^{\mathrm{b}}$ \\ ${ }^{a}$ Estonian Marine Institute, University of Tartu, Mäealuse 10a, 12618 Tallinn, Estonia \\ b Tallinn Pedagogical University, Narva mnt. 25, 10120 Tallinn, Estonia; katrin.valjataga.001 @ mail.ee \\ Received 10 December 2002, in revised form 7 October 2004
}

\begin{abstract}
The Ponto-Caspian predatory cladoceran Cercopagis pengoi was first found in the Gulf of Finland in 1992. The distribution of the species was followed in 1997-2002 in relation to selected most important abiotic and biotic environmental factors. The abundance of $C$. pengoi was best explained by thermal stratification and density of Cladocera. The significant negative correlations between the vertical distribution of the small cladoceran Bosmina coregoni maritima and the abundance of $C$. pengoi indicate that $C$. pengoi affects the vertical distribution of its potential prey B. c. maritima.
\end{abstract}

Key words: Cercopagis pengoi, invasion, Baltic Sea, Bosmina coregoni maritima.

\section{INTRODUCTION}

The invasive living organisms have become one of the most serious threats to the aquatic ecosystems during the last 10-20 years causing unpredictable and irreversible changes in the recipient ecosystems (Carlton, 1996; Ruiz et al., 1999). The transfer of ballast water between ports has served as an important vector, enabling the invasion of many aquatic species to new habitats (Carlton \& Hodder, 1995). Taking into account the position of the Gulf of Finland as an active area of international shipping routes and large ports, the high rate of alien species introductions into the gulf and their possible negative impacts on the environment, the Gulf of Finland should be considered as a "hot spot" in the Baltic Sea region.

\footnotetext{
* Corresponding author, arno@sea.ee
} 
The most recent planktonic newcomer in the Gulf of Finland and the whole Baltic Sea is the predatory cladoceran Cercopagis pengoi. The species was first observed in the Gulf of Finland in 1992; most likely it was introduced as a result of ballast water releases (Ojaveer et al., 2000). During the second half of the 1990s the species colonized almost the whole Baltic Sea from the north (Bothnian Bay) to the south (Gulf of Gdansk) (e.g., Bielecka et al., 2000; Gorokhova et al., 2000). Unfortunately, there are few data available on the effect of the environment on the dynamics of $C$. pengoi and the impact of the species on the native biota in the Gulf of Finland (e.g. Krylov et al., 1999; Uitto et al., 1999).

The aim of the present study is to relate the distribution of $C$. pengoi to various abiotic and biotic variables and to test whether $C$. pengoi affects the distribution of its potentially essential prey Bosmina coregoni maritima in the Gulf of Finland. The study is based on the zooplankton and environmental monitoring data collected in 1997-2002.

\section{MATERIAL AND METHODS}

Zooplankton samples were collected under the frame of the Estonian National Monitoring Programme. The strategy and frequency of sampling varied between years. The samples were taken at stations near Tallinn Bay in 1997-2002 and in Narva Bay in 2001-2002 (Fig. 1). The sampling was done fortnightly from March

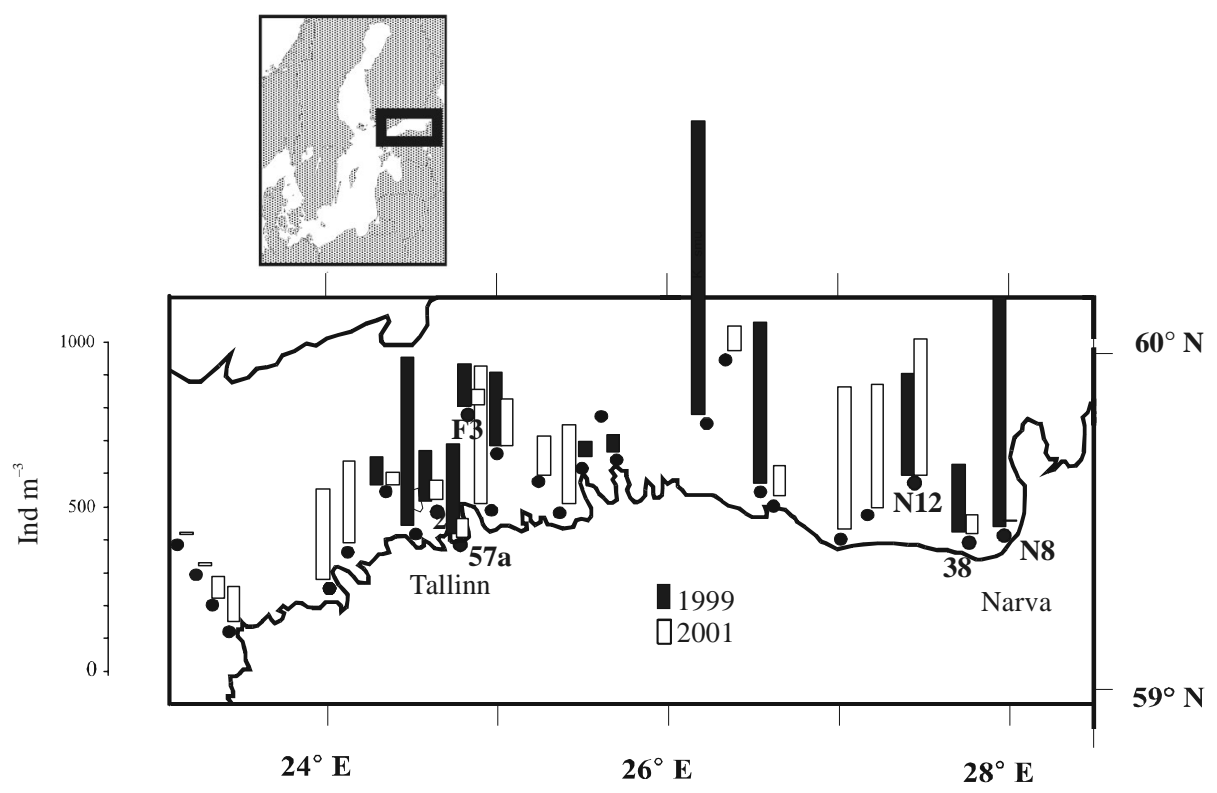

Fig. 1. Location of sampling stations and abundance of Cercopagis pengoi (ind $\mathrm{m}^{-3}$ ) in August 1999 and 2001. Frequent sampling was performed at stations 57a, 2, and F3 (Tallinn) and N12, N8, and 38 (Narva). 
to August and monthly in September to November. The data on the horizontal distribution of $C$. pengoi in the whole coastal area of the Gulf of Finland were obtained in August 1999 and in August 2001. The samples were collected by means of vertical tows with Juday closing plankton net (mesh size $90 \mu \mathrm{m}$, mouth area $0.1 \mathrm{~m}^{2}$ ) and preserved in $4 \%$ formalin. In order to calculate the abundance of C. pengoi, all individuals in a sample were counted.

The effect of $C$. pengoi on the vertical distribution of B. c. maritima was studied using samples from July to September 1999 and 2001, i.e. the years of most representative sampling and relatively high abundance of $C$. pengoi. The percentage of the population of B. c. maritima above and below the thermocline was calculated.

Additional environmental parameters used in statistical analyses were temperature, salinity measured with CTD, Secchi depth, and chlorophyll $a$ measured in integrated water from depths $0-10 \mathrm{~m}$ according to HELCOM (1988) recommendations. These parameters were routinely monitored during zooplankton sampling. STATISTICA 6.0 and Primer 5.0 were used for statistical analyses.

\section{RESULTS AND DISCUSSION}

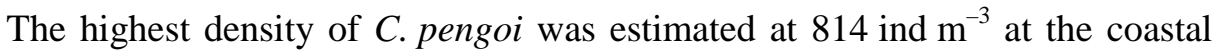
station of Narva Bay in September 2002. Population densities over 700 ind $\mathrm{m}^{-3}$ were observed annually since 1999 . In 2000, however, the maximum density was only 220 ind $\mathrm{m}^{-3}$. As sampling was ended at the beginning of August and the sampling frequency was relatively low, the potential peak period of the population was probably not observed. No massive occurrence of $C$. pengoi was observed in 1997 and 1998. The average density of $C$. pengoi when present in a sample was 154 ind $\mathrm{m}^{-3}$ in 1997-2002. Excluding a few samples taken below the thermocline the average was 190 ind $\mathrm{m}^{-3}$.

Thermal stratification was an important variable for the dynamics of $C$. pengoi (see BIOENV analysis below). The density of the cladoceran increased with rising temperature stratification (e.g., with decreasing wind stress). Differences in thermal stratification may explain the large-scale variability of $C$. pengoi populations in different basins of the Baltic Sea. For example, the southern coastal areas of the Gulf of Finland are hydrodynamically more active than its less exposed northern coasts and the Gulf of Riga. Also, the densities of $C$. pengoi were about 5-10 times higher in the Gulf of Riga and less exposed areas of the Gulf of Finland than at our sampling sites (Uitto et al., 1999; Ojaveer et al., 2004; and this study).

Although the frequency of sampling was relatively low, some conclusions on the seasonal dynamics of $C$. pengoi in the Gulf of Finland can be drawn. The cladoceran was usually first observed at temperatures above $15^{\circ} \mathrm{C}$ in July. The highest densities were found a few weeks after the initial occurrence. The population disappeared at temperatures below $15^{\circ} \mathrm{C}$ in September-October. Earlier studies have 
also stressed the importance of temperature for the development of C. pengoi in the Baltic Sea area (Avinski, 1997; Uitto et al., 1999; Ojaveer et al., 2004). The cercopagids are considered typical warm-water species and the mass occurrence of C. pengoi coincides with high water temperature (Ojaveer \& Lumberg, 1995; Krylov et al., 1999; Uitto et al., 1999). However, some specimens can be found at temperatures below $10^{\circ} \mathrm{C}$, but no mass occurrence at such temperatures has been reported. In some cases $C$. pengoi had two density peaks during the same season. A similar behaviour has been earlier recorded in the Neva estuary (Krylov et al., 1999).

The abundance of $C$. pengoi was best explained by thermal stratification and density of Cladocera (BIOENV Spearman $\rho=0.543$ ). There was a significant but weak correlation between the densities of B. c. maritima and C. pengoi (linear correlation analysis $R=0.23, p<0.05$ ).

The two species tend to share the same habitat in the Gulf of Finland. There were only two samples where the abundance of B. c. maritima exceeded $1000{\text { ind } \mathrm{m}^{-3}}^{-3}$ and $C$. pengoi was not present. The average abundance of $B$. c. maritima in samples with $C$. pengoi was 6600 ind $\mathrm{m}^{-3}$. The effect of predatory $C$. pengoi on the potential prey species B. c. maritima was estimated by the Spearman correlation product between the abundance of $C$. pengoi and the percentage of B. c. maritima above the thermocline. The results revealed that $B$. c. maritima tended to stay below the thermocline at higher abundances of $C$. pengoi above the thermocline $(R=-0.61$, $p<0.01$ ). Two BIOENV analyses, one with environmental variables and abundance of $C$. pengoi and the other with abundances of all zooplankton species, were performed to seek the best combination of environmental variables determining the distribution of B. c. maritima (Table 1). Almost all combinations of zooplankton species with a high correlation to B. c. maritima contained nauplii of Balanus improvisus and Keratella cochlearis. Often also C. pengoi was included. BIOENV with only environmental parameters and abundance of $C$. pengoi included pointed most frequently to $C$. pengoi as the prime factor determining the distribution of B. c. maritima. It is unlikely that the nauplii of B. improvisus or $K$. cochlearis have some direct impact on the vertical distribution of B. c. maritima. There are probably some other environmental factors that influence all three species in the same way. The predatory $C$. pengoi may on the other hand be one of the main factors causing changes in the vertical distribution of B. c. maritima. No diurnal vertical migration of $C$. pengoi has been recorded in the Baltic Sea area and the majority of the population are located in the upper water layer (Gorokhova et al., 2000). Hence, the deeper water layers may be considered as a refuge for the prey species such as B. c. maritima.

Previous studies from other basins show that the introduction of $C$. pengoi has in many cases led to significant changes in the composition and abundance of zooplankton in recipient ecosystems (Kotta et al., 2004; Ojaveer et al., 2004). The cladoceran is a voracious predator, which feeds on smaller cladocerans and copepod nauplii (A. Lankov, H. Ojaveer, A. Põllumäe \& M. Simm, unpubl. data). 
Table 1. Results of two BIOENV analyses indicating the most important factors determining the vertical distribution of Bosmina coregoni in the Gulf of Finland

\begin{tabular}{|c|c|c|c|c|}
\hline \multicolumn{5}{|c|}{ BIOENV: 1, Zooplankton taxa determining the distribution of Bosmina } \\
\hline & Variable & $\begin{array}{c}\text { Number } \\
\text { of variables }\end{array}$ & Correlation & Selections \\
\hline 1 & Cercopagis pengoi & 2 & 0.464 & 4,8 \\
\hline 2 & Acartia spp. & 3 & 0.41 & $4,8,9$ \\
\hline 3 & Balanus improvisus nauplii & 4 & 0.392 & $1,4,8,9$ \\
\hline 4 & Bivalvia larvae & 1 & 0.389 & 8 \\
\hline 5 & Cyclopidae & 3 & 0.384 & $1,4,8$ \\
\hline 6 & Eurytemora affinis & 5 & 0.365 & $1,4,8,9,15$ \\
\hline 7 & Evadne nordmanni & 5 & 0.364 & $1,4,6,8,9$ \\
\hline 8 & Keratella cochlearis & 4 & 0.356 & $4,6,8,9$ \\
\hline 9 & Keratella cruciformis & 5 & 0.353 & $1,4,8-10$ \\
\hline 10 & Keratella quadrata & 3 & 0.353 & $4,8,12$ \\
\hline 11 & Calanoid nauplii & & & \\
\hline 12 & Pleopsis polyphemoides & & & \\
\hline 13 & Podon intermedius & & & \\
\hline 14 & Synchaeta baltica & & & \\
\hline 15 & Synchaeta monopus & & & \\
\hline 16 & Temora longicornis & & & \\
\hline \multicolumn{5}{|c|}{ BIOENV: 2, Various factors determining the location of Bosmina } \\
\hline & Variable & $\begin{array}{c}\text { Number } \\
\text { of variables }\end{array}$ & Correlation & Selections \\
\hline 1 & Month & 1 & 0.245 & 3 \\
\hline 2 & Daylight & 2 & 0.241 & 3,8 \\
\hline 3 & Cercopagis pengoi & 3 & 0.235 & $3,5,8$ \\
\hline 4 & Station No./Horizon & 2 & 0.213 & 3,5 \\
\hline 5 & Station depth & 3 & 0.194 & $3,8,9$ \\
\hline 6 & Temperature at the end of tow & 4 & 0.187 & $3,5,7,8$ \\
\hline 7 & Temperature at the start of tow & 4 & 0.186 & $3,5,8,9$ \\
\hline 8 & Salinity & 4 & 0.181 & $3,5,6,8$ \\
\hline \multirow[t]{2}{*}{9} & Number of zooplankton taxa & 3 & 0.18 & $3,7,8$ \\
\hline & & 3 & 0.171 & $3,6,8$ \\
\hline
\end{tabular}

Relying on the current database, it is impossible to say whether the average abundance of B. c. maritima has decreased after the invasion of $C$. pengoi in the Gulf of Finland as it happened in the Gulf of Riga (Kotta et al., 2004; Ojaveer et al., 2004). The current data reveal no significant decline of B. c. maritima in the Gulf of Finland.

Temperature stratification and the density of cladocerans seem to be the most important environmental variables explaining the distribution of $C$. pengoi in the Gulf of Finland. As indicated in this study densities of the alien species are high enough to have an impact on the distribution of its potential prey B. c. maritima. 
Our study points to the need of manipulative experiments in order to demonstrate the causative links between the dynamics of $C$. pengoi and the native zooplankton communities in recipient ecosystems.

\section{ACKNOWLEDGEMENTS}

The current study was supported by the Estonian Governmental Fundamental Research Programme No.0182579s03. Funding was also obtained through a US Government grant (SEN100-02-GR069). The opinions, findings, and conclusions expressed herein are those of the authors and do not necessarily reflect those of the US Government.

\section{REFERENCES}

Avinski, V. 1997. Cercopagis pengoi - a new species in the eastern Gulf of Finland ecosystem. In Proceedings of the Final Seminar of the Gulf of Finland Year 1996. March 17-18, Helsinki, Finland (Sarkkula, J., ed.), pp. 247-256. Suomen Ympäristokeskus, Helsinki.

Bielecka, L., Zmijevska, M. I. \& Szymbonska, A. 2000. A new predatory cladoceran Cercopagis (Cercopagis) pengoi (Ostroumov 1891) in the Gulf of Gdansk. Oceanologia, 42, 371-374.

Carlton, J. T. 1996. Pattern, process, and prediction in marine invasion ecology. Biol. Conserv., 78, 97-106.

Carlton, J. T. \& Hodder, J. 1995. Biogeography and dispersal of coastal marine organisms: experimental studies on a replica of a 16th-century sailing vessel. Mar. Biol., 121, 721-730.

Gorokhova, E., Aladin, N. \& Dumont, H. 2000. Further expansion of the genus Cercopagis (Crustacea, Branchiopoda, Onychopoda) in the Baltic Sea, with notes on the taxa present and their ecology. Hydrobiologia, 429, 207-218.

HELCOM. 1988. Guidelines for the Baltic Monitoring Programme for the third stage. Baltic Sea Environ. Proc., 27D.

Kotta, J., Simm, M., Kotta, I., Kanošina, I., Kallaste, K. \& Raid, T. 2004. Factors controlling longterm changes of the eutrophicated ecosystem of Pärnu Bay, Gulf of Riga. Hydrobiologia, 514, 259-268.

Krylov, P. I., Bychenkov, D. E., Panov, V. E., Rodionova, N. V. \& Telesh, I. V. 1999. Distribution and seasonal dynamics of the Ponto-Caspian invader Cercopagis pengoi (Crustacea, Cladocera) in the Neva Estuary (Gulf of Finland). Hydrobiologia, 393, 227-232.

Ojaveer, H. \& Lumberg, A. 1995. On the role of Cercopagis (Cercopagis) pengoi (Ostroumov) in Pärnu Bay and the NE part of the Gulf of Riga ecosystem. Proc. Estonian Acad. Sci. Ecol., 5, 20-25.

Ojaveer, H., Simm, M., Lankov, A. \& Lumberg, A. 2000. Consequences of invasion of a predatory cladoceran Cercopagis pengoi to the Baltic Sea. ICES J. Mar. Sci., CM2000/U:16.

Ojaveer, H., Simm, M. \& Lankov, A. 2004. Population dynamics and ecological impact of the nonindigenous Cercopagis pengoi in the Gulf of Riga (Baltic Sea). Hydrobiologia, 522, 261-269.

Ruiz, G. M., Fofonoff, P. \& Hines, A. H. 1999. Non-indigeneous species as stressors in estuarine and marine communities: assessing invasion impacts and interactions. Limnol. Oceanogr., 44, 950-972.

Uitto, A., Gorokhova, E. \& Välipakka, P. 1999. Distribution of the non-indigenous Cercopagis pengoi in the coastal waters of the eastern Gulf of Finland. ICES J. Mar. Sci., 56, 49-57. 


\title{
Cercopagis pengoi (Cladocera) Soome lahes: erinevate keskkonnaparameetrite mõju ruumilisele jaotusele ja suhtele liigiga Bosmina coregoni maritima
}

\begin{abstract}
Arno Põllumäe ja Katrin Väljataga
Cercopagis pengoi leiti Soome lahest esmakordselt 1992. aastal. Aastatel 1997-2002 läbi viidud uuringute järgi vaadeldi liigi levikut ja selle sõltuvust tähtsamatest abiootilistest ja biootilistest keskkonnateguritest. C. pengoi jaotust mõjutasid kõige tugevamalt vee termiline kihistumine ja vesikirbuliste arvukus. Oluline korrelatsioon C. pengoi arvukuse ja Bosmina coregoni maritima vertikaalse jaotuse vahel näitab, et $C$. pengoi põhjustab oma potentsiaalse toiduobjekti B. c. maritima vertikaalset migratsiooni.
\end{abstract}

